\title{
Kemampuan Mahasiswa PGMI dalam Mengembangkan Soal Berbasis Literiasi Sains
}

\author{
Received: \\ $30 / 12 / 2021$ \\ ${ }^{1}$ Bungawati, ${ }^{2}$ Ervi Rahmadani \\ Accepted: \\ $31 / 12 / 2021$ \\ Institut Agama Islam Negeri Palopo, Palopo, Indonesia \\ ${ }^{1}$ bungawati@iainpalopo.ac.id
}

Published:

$31 / 12 / 2021$

\begin{abstract}
This study aims to determine the ability of PGMI students in developing scientific literacy-based questions in science learning in MI/SD. The research method used is qualitative with descriptive analysis. The results of the study found that the ability of students to develop scientific literacy-based questions on the competency dimension was in the good category, the content dimension was in the good category, the science context dimension was in the very good category and the scientific attitude category was in the poor category. It can be concluded that the students' ability in developing scientific literacy-based questions is in the good category.
\end{abstract}

Keywords: Student ability; science learning; scientific literacy

\begin{abstract}
Abstrak
Penelitian ini bertujuan untuk mengetahui kemampuan mahasiswa PGMI dalam mengembangkan soal berbasis literasi sains pada pembelajaran IPA di MI/SD. Metode penelitian yang digunakan adalah kualitatif dengan analisis deskriptif. Hasil penelitian ditemukan bahwa kemampuan mahasiswa dalam mengembangkan soal berbasis literasi sains pada dimensi kompetensi dalam kategori baik, dimensi konten dalam kategori baik, dimensi konteks sains dalam kategori sangat baik dan kategori sikap ilmiah kategori kurang. Dapat disimpulkan bahwa kemampuan mahasiswa dalam mengembangkan soal berbasis literasi sains berada pada kategori baik.
\end{abstract}

Kata kunci: kemampuan mahasiswa; pembelajaran IPA; literasi sains

\section{Pendahuluan}

Pendidikan adalah pondasi yang menentukan keberhasilan suatu bangsa di masa yang akan datang. Mahasiswa sebagai calon pemegang kuasa sekaligus penentu mutu Pendidikan Indonesia di masa yang akan datang haruslah memiliki bekal dan keahlian yang sesuai dengan bidang pendidikannya. Seorang mahasiswa dituntun dan dituntut untuk terus mengasah kemampuannya tidak hanya untuk memahami materi tetapi juga dituntut untuk terus meningkatkan kemampuan psikomotoriknya. Hal demikian pun berlaku bagi mahasiswa Pendidikan Guru Madrasah Ibtidaiyah (PGMI). Sebagai calon pendidik generasi Alpha, mahasiswa haruslah memiliki keahlian yang mumpuni sebagai bekal untuk meningkatkan mutu pendidikan di masa yang akan datang. Bekal yang harus dikuasai calon pendidik seperti merencakan pembelajaran, mengelolah kelas, melaksanakan pembelajaran hingga mengevaluasi kegiatan pembelajaran yang telah dilaksanakan. Evaluasi yang dilakukan dalam kegiatan pembelajaran merupakan alat ukur untuk melihat sejauh mana tingkat pencapaian peserta didik dalam pelaksanaan pembelajaran. Salah satu alat evaluasi yang dapat digunakan yaitu tes 


\section{2 | Bungawati dan Ervi Rahmadani}

dengan menggunakan soal-soal yang disiapkan oleh guru. Calon guru harus melibatkan siswa dalam kegiatan-kegiatan ilmiah seperti keterampilan literasi sains (Rini, C.P., Hartantri, S.D., \& Amaliyah, 2021).

Keterampilan yang harus dikuasai oleh calon guru Pendidikan dasar yaitu meningkatkan kemampuan literasi di tingkat dasar. Kemampuan literasi menjadi hal yang meresahkan pada abad ini. Berdasarkan penelitian yang dilakukan oleh Early Grade Reading Assesment (EGRA) pada tahun 2012 menyatakan bahwa kurang dari 50 persen siswa Sekolah Dasar mahir membaca dan paham apa yang mereka baca, hanya $26 \%$ siswa dapat menjawab 3 dari 5 pertanyaan dengan benar dan 5,8 \% siswa tidak dapat membaca sama sekali (Kemendikbud, 2019). Selang 7 tahun kemudian, tepatnya pada tahun 2019 lalu Program for International Student Assesment (PISA) yang dirilis Organization for Economic Co-operation and Development (OECD) menyatakan bahwa tingkat literasi masyarakat Indonesia tergolong sangat rendah, menempati ranking ke 62 dari 70 negara, atau berada pada 10 negara terbawah (Retno, 2021). Negara kita jauh tertinggal dari negara-negara seperti Finlandia. Hal ini disebabkan oleh beberapa faktor, salah satunya yaitu masih rendahnya budaya membaca di Indonesia.

Literasi sains dapat diartikan sebagai pengetahuan dan kecakapan ilmiah untuk mampu mengidentifikasi pertanyaan, memperoleh pengetahuan baru, menjelaskan fenomena ilmiah, serta mengambil simpulan berdasarkan fakta, memahami karakteristik sains, kesadaran bagaimana sains dan teknologi membentuk lingkungan alam, intelektual, dan budaya, serta kemauan untuk terlibat dan peduli terhadap isu-isu yang terkait sains (OECD dalam kemdikbud, 2017). OECD (2013) mendefinisikan literasi sains sebagai (1) pengetahuan ilmiah individu dan kemampuan untuk menggunakan pengetahuan tersebut utnuk mengidentifikasi masalah, memperoleh pengetahuan baru, menjelaskan fenomena ilmiah, dan menarik kesimpulan berdasarkan bukti yang berhubungan dengan isu sains; (2) memahami karakteristik utama pengetahuan yang dibangun dari pengetahuan manusia dan inkuiri; (3) peka terhadap bagaimana sains dan teknologi membentuk materia, lingkungan intelektual dan budaya; (4) adanya kemauan untuk terlibat dalam isu dan ide yang berhubungan dengan sains. Kemudian pengertian tersebut kembali disederhanakan oleh Toharuddin dkk. (2013) yang mendefinisikan literasi sains sebagai kemampuan sesorang untuk memahami sains, mengomunikasikan sains (lisan dan tulisan), serta menerapkan pengetahuan sains untuk memecahkan masalah sehingga memiliki sikap dan kepekaan yang tinggi terhadap diri dan lingkungannya dalam mengambil keputusan berdasarkan pertimbangan-pertimbangan sains. PISA pada tahun 2015 menetapkan literasi sains terdiri dari 4 dimensi (aspek) besar yang saling berhubungan yaitu kompetensi (proses sains), konten sains (pengetahuan sains), konteks sains dan sikap ilmiah (Jufri, 2017)

Literasi Sains hadir untuk membentuk pola pikir, perilaku dan membangun karakter manusia untuk peduli dan bertanggung jawab terhadap dirinya, masyarakat dan alam semesta (Hidayati \& Julianto, 2018). Oleh karena itu salah satu faktor pendukung untuk meningkatkan literasi sains siswa sekolah dasar yaitu guru agar terbentuk generasi penerus bangsa yang berkualitas yang memiliki ilmu pengetahuan untuk memenuhi tuntutan zaman. Kondisi seperti inilah yang menuntut adanya perubahan-perubahan inovasi yang harus dilakukan oleh calon guru baik dalam pembelajaran maupun dalam melakukan penilaian. Literasi sains merupakan keterampilan untuk hidup di Era abad 21 dimana pengetahuan ilmiah menjadi landasan dalam kehidupan sehari-hari (Gultepe \& Kilic, 2015). Hal senada diungkapkan oleh Kelana (2019) yang menyatakan bahwa guru dituntut membuat bacaan disertai dengan soal-soal yang berkaitan dengan literasi sains. Adapun tujuan dari penelitian ini untuk mengetahui kemampuan

JUDIKDAS: Jurnal Ilmu Pendidikan Dasar Indonesia Volume 1 - No. 1 
mahasiswa PGMI dalam mengembangkan soal berbasis literasi sains pada pembelajaran IPA di MI/SD.

\section{Metode Penelitian}

Metode penelitian yang digunakan dalam penelitian ini adalah penelitian kualitatif guna untuk menggambarkan kualitas kemampuan mahasiswa PGMI dalam mengembangkan soal berbasis literasi sains pada mata kuliah pembelajaran IPA MI/SD. Teknik analisis data yang digunakan secara deskriptif yang bertujuan menarasikan sifat kejadiaan selama pengambilan data. Penelitian ini menggunakan dokumentasi dan daftar check list. Peneliti mengumpulkan data-data berupa lembar jawaban dari mahasiswa kemudian mengisi daftar chek list berdasarkan dimensi literasi sains. Subyek penelitian yaitu mahasiswa semester 3 Prodi PGMI IAIN Palopo pada mata kuliah Pembelajaran IPA yang berjumlah 28 orang.

Tabel 1 Dimensi Literasi Sains

\begin{tabular}{|c|c|c|}
\hline No & Dimensi & Indikator \\
\hline \multirow[t]{3}{*}{1} & \multirow[t]{3}{*}{ Kompetensi (proses sains) } & $\begin{array}{l}\text { Mengidentifikasi pertanyaan atau isu-isu } \\
\text { ilmiah }\end{array}$ \\
\hline & & Menjelaskan fenomena secara ilmiah \\
\hline & & Menggunakan bukti ilmiah \\
\hline \multirow[t]{3}{*}{2} & \multirow[t]{3}{*}{ Konten (pengetahuan sains) } & Pengetahuan konten \\
\hline & & Pengetahuan prosedural \\
\hline & & Pengetahuan epistemik \\
\hline \multirow[t]{5}{*}{3} & \multirow[t]{5}{*}{ Konteks sains } & Bidang Kesehatan \\
\hline & & Sumber daya alam \\
\hline & & Mutu lingkungan \\
\hline & & Bahaya \\
\hline & & $\begin{array}{l}\text { Dampak perkembangan mutakhir sains dan } \\
\text { teknologi }\end{array}$ \\
\hline \multirow[t]{6}{*}{4} & \multirow[t]{6}{*}{ Sikap ilmiah } & Rasa ingin tahu \\
\hline & & Tanggung jawab \\
\hline & & Percaya diri \\
\hline & & Punya motivasi tinggi \\
\hline & & Pemahaman diri \\
\hline & & Nilai-nilai \\
\hline
\end{tabular}

Tabel 2 Kategori Kemampuan Mahasiswa Membuat Soal Berbasis Literasi Sains

\begin{tabular}{ll}
\hline Interval & Kategori \\
\hline $85-100$ & Sangat baik \\
\hline $75-84$ & Baik \\
\hline $65-74$ & Cukup \\
\hline Kurang dari 64 & Kurang \\
\hline
\end{tabular}

(Suhendro, 2016)

\section{Hasil}

Penelitian ini dilakukan dengan cara mengambil data hasil dari tugas mata kuliah yang peneliti ampuh yaitu mata kuliah Pembelajaran IPA MI/SD. Kegiatan awal dari penelitian ini

\section{JUDIKDAS: Jurnal Ilmu Pendidikan Dasar Indonesia}

Volume 1 - No. 1 


\section{4 | Bungawati dan Ervi Rahmadani}

adalah melakukan kegiatan perkuliahan, kemudian memberikan tugas kepada mahasiswa untuk membuat tiga soal pilihan ganda berbasis literasi sains. Hasil tugas yang telah selesai kemudian dikumpulkan, diolah, dianalisis selanjutnya digeneralisasikan sehingga diperoleh kesimpulan berdasarkan data yang ada. Pada penyajian hasil penelitian akan dipaparkan data dari indikator setiap dimensi literasi sains. Adapun lemampuan mahasiswa dalam mengambangkan soal berbasis literasi sains disajikan pada Tabel 3 berikut ini:

Tabel 3 Hasil penelitian

\begin{tabular}{|c|c|c|c|}
\hline Dimensi & Skor perolehan & Persentase & Kategori \\
\hline Kompetensi (proses sains) & 23 & 77 & Baik \\
\hline Konten (pengetahuan sains) & 24 & 80 & Baik \\
\hline Konteks sains & 28 & 100 & Sangat baik \\
\hline Sikap ilmiah & 18 & 60 & Kurang \\
\hline Rata-rata & 80 & & Baik \\
\hline
\end{tabular}

Berdasarkan tabel 3 di atas dapat diketahui bahwa rata-rata dimensi hasil penelitian yang telah dilakukan menunjukkan kemampuan mahasiswa calon guru program studi Pendidikan Guru Madrasah Ibtidaiyah (PGMI) berada pada kategori baik. Hal tersebut dapat dilihat dari perolehan nilai persentase $80 \%$. Meskipun skor rata-rata berada pada kategori baik, namun pada salah satu dimensi literasi sains yaitu sikap ilmiah masih berada pada kategori kurang, yang berarti masih harus ditingkatkan.

\section{Diskusi}

\section{Dimensi Kompetensi}

Pada dimensi kompetensi, kemampuan siswa berada bada kategori baik yaitu mahasiswa dapat membuat soal dengan mengidentifikasi pertanyaan atau isu ilmiah, menjelaskan fenomena secara ilmiah dan menggunakan bukti ilmiah. Sebanyak 23 mahasiswa mampu membuat soal dengan memperhatikan dimensi kompetensi, masih ada 5 mahasiswa yang belum mampu menerapkan dimensi kompetensi dalam membuat soal pilihan ganda berbasis literasi sains. Dimensi kompetensi biasa disebut dengan proses sains yang berarti proses seseorang dalam menjawab suatu pertaanyaan atau masalah ilmiah termasuk mengenal jenis pertanyaan mengenal bukti serta mengenal kesimpulan yang sesuai dengan bukti yang ada.

Proses literasi sains mengkaji kemapuan mahasiswa untuk menggunakan pengetahuan ilmiah, seperti mencari, menafsirkan dan memperlakukan bukti-bukti. Untuk membangun kemampuan literasi sains paada diri siswa, yang berlandaskan pada logika, penalaraan daan analisis kritis dan kreatif (Jufri, 2017). Penelitian sebelumnya menyatakan bahwa kemampuan siswa dalam menganalisis soal, siswa harus memahami bukti yang berupa data yang diberikan oleh guru pada soal evaluasi. Melalui hal tersebut maka siswa menjadi terlatih dalam menggunakan bukti yang diperoleh secara ilmiah (Fitriani, dkk, 2017).

\section{Dimensi Konten}

Soal yang dikembangkan oleh mahasiswa pada dimensi konten mendapat persentase $80 \%$ berada pada kategori baik. Mahasiswa mampu meramu soal dengan menerapkan pengetahuan konten, pengetahuan prosedural maupun pengetahuan epistemik. Soal yang dibuat relevan dengan keadaan yang sebenarnya serta sesuai dengan usia perkembangan peserta didik. Konten sains merujuk pada konsep-konsep dasar dari sains yang diperlukan untuk memahami 
fenomena alam dan perubahan yang dilakukan terhadaap alam melalui kegiatan manusia. Kriteria pemilihan konten sains adalah relevan dengan situasi nyata dan merupakan pengetahuan penting dan penggunaannya berjangka panjang. Konten sains tidak hanya pada pengetahuan yang menjadi sumber bahan ajar pada kurikulum yang ada di sekolah dasar melainkan dapat pula dari berbagai sumber informasi dari sains dan teknologi yang terpercaya.

\section{Konteks sains}

Kemampuan mahasiswa membuat soal pada dimensi konteks sains memperoleh persentase $100 \%$ berada pada kategori sangat baik. Hal tersebut terjadi karena seluruh butir soal yang dibuat memuat indikator konteks sains yaitu bidang kesehatan, sumber daya alam serta mutu lingkungan. Konteks adalah area aplikasi konseop-konsep sains yang tediri dari kesehatan, sumber daya alam, lingkungan, bahaya, sains, dan teknologi yang aplikasinya secara personal, social dan global. Konteks sains dalam PISA merujuk pada kehidupan sehari-hari daripada kelas atau laboratorium dengan melibatkan isu-isu yang sangat penting dalam kehidupan secara umum seperti kepedulian pribadi (Toharuddin, 2013). Adapun upaya yang dapat dilakukan pada sekolah tingkat dasar yaitu menceritakan pengalaman dari penyampaian konsep-konsep dalam relasi, merangkainya dalam kalimat dalam konteks bacaan untuk membangun konsep sains yang lebih kristis (Fitriani, 2017).

\section{Sikap Ilmiah}

Pada dimensi sikap ilmiah diperoleh persentase sebesar 60\% yang berada pada kategori cukup. Mahasiswa belum mampu meningkatkan rasa ingin tahu peserta didik. Dalam Toharudin (2013) yang termasuk dalam domain sikap ilmiah adalah respon terhadap isu sains, minat, mendukung inkuiri ilmiah dan tanggung jawab. Apabila kemampuan literasi sains khususnya pada dimensi sikap ilmiah masih kurang, maka dikhawatirkan proses pembelajaran IPA berlangsung kurang baik sehingga menyebabkan kemampuan peserta didik dalam memahami IPA juga rendah (Rini, C.P., Hartantri, S.D., \& Amaliyah, 2021). Hal ini masih perlu menjadi perhatian mahasiswa agar meningkatkan dimensi sikap ilmiah.

Berdasarkan dari beberapa data yang telah diperoleh bahwa masih dibutuhkan berbagai upaya dalam meningkatkan kemampuan literasi sains mahasiswa salah satunya mengajarkan mereka untuk mengungkapkan pikiran, pilihan kata berkaitan dengan pengungkapan pikiran, pengembangan paragraf dan penggunaan pernyataan untuk menunjang pendapat.

\section{Kesimpulan}

Secara umum mahasiswa telah mengetahui keempat dimensi literasi sains dan mampu mengembangkan soal yang berbasis literasi sains, hal ini terlihat dari persentase rata-rata yaitu 80. Dapat disimpulkan bahwa kemampuan mahasiswa Program Studi Pendidikan Guru Madrasah Ibtidaiyah secara umum berada pada kategori baik. Dalam menyusun soal berbasis literasi sains keempat dimensi tidak dapat dipisahkan. Bila salah satu dimensi tidak maksimal maka akan berpengaruh pada kemampuan membuat soal. Calon guru harus mampu mengambil peran dalam pengembangan kemampuan literasi sains pada masa yang akan datang. Salah satu lang yang bisa diambil yaitu meningkat kemampuannya dalam membuat soal berbasis literasi sains. 


\section{Referensi}

Fitriani, D., Burhannudin, M., Dedi I. 2017. Pengaruh Model Pembelajaran Berbasis Masalah Terhadap Kemampuan Literasi Sains Siswa pada Materi Laju Reaksi. Edusains, 9(2) hal 117-126. http:/ /journal.uinjkt.ac.id/index.php/edusains.

Fitria, Y. 2017. Pembelajaran Literasi Sains untuk Level Dasar. Hal. 30-40. Padang: Jurusan PGSD FIP UNP. Diakses dari http://repository.unp.ac.id/15728/1/Prosiding\%20Semnas\%2045\%20agustus\%202017\%201.pdf, tanggal 29 Desember 2021.

Gultepe, N. \& Kilic, Z. 2015. Effect of scientific argumentation on the development of scientific process skills in the context of teaching chemistry. International Journal of Environmental and Science Education, 10(1), 111-132.

Hidayati, F., \& Julianto. (2018). Penerapan Literasi Sains dalam Pembelajaran IPA di Sekolah Dasar untuk Meningkatkan Kemampuan Berfikir Kritis Siswa dalam Memecahkan Masalah. In Seminar Nasional Pendidikan (pp. 180-184).

Jufri, Wahab A. 2017. Belajar dan Pembelajaran Sains (Modal Dasar Menjadi Guru Profesional). Bandung: Pustaka Reka Cipta.

Kelana, J. B. dan Fadly Pratama. 2019. Bahan Ajar IPA berbasis Literasi Sains. Bandung: Lekkas. Diakses dari https://www.researchgate.net/profile/JajangKelana/publication/336320942_BAHAN_AJAR_IPA_BERBASIS_LITERASI_SAI NS/links/5f5ad6c1299bf1d43cf98814/BAHAN-AJAR-IPA-BERBASIS-LITERASISAINS.pdf, tanggal 29 Desember 2021.

Kemendikbud. (2019). Indeks Aktivitas Literasi Membaca 34. In Pusat Penelitian Kebijakan Pendidikan dan Kebudayaan, Badan Penelitian dan Pengembangan, Kementerian Pendidikan Kan Kebudayaan (Issue 2). http://repositori.kemdikbud.go.id/13033/1/Puslitjakdikbud_Indeks Aktivitas Literasi Membaca 34 Provinsi.

Kementerian Pendidikan dan Kebudayaan. (2017). Materi Pendukung Literasi Sains. Gerakan Literasi Nasional, 1-36.

OECD. 2013. PISA 2012 Assesmen and Anatical Framework: Mathematics, Reading, Science, Problem Solving and Financial Literacy. OECD Publishing; Paris-France.

Retno, Heriyanto. 2021. Miris, Minat Baca di Indonesia Menurut Unesco Hanya 0,001 persen. Portal Bandung Timur. https://portalbandungtimur.pikiranrakyat.com/pendidikan/pr-941922838/miris-minat-baca-di-indonesia-menurutunesco-hanya-0001-persen, diakses tanggal 27 Desember 2021

Rini, C.P., Hartantri, S.D., \& Amaliyah, A. (2021). the Analysis of Scientific Literacy on Pgsd Students ' Competency At Univesity of. Jurnal Pendidkan Dasar Nusantara, 6, 166-179.

Suhendro., Sarjan, N., Husaun., \& Djirimu, M. 2016. “Meningkatkan Hasil Belajar Siswa Mata Pelajaran IPA (Bagian-bagian Tumbuhan) dengan Pemanfaatan Lingkungan Alam Sekita Kelas IV SDK Padat karya". Jurnal Kreatif Tadulako Online, 4 (5). 
Toharuddin, U., Hendrawati, S., dan Rustaman, A. 2013. Membangun Literasi Sains Peserta Didik. Bandung: Humaniora. 
88 | Bungawati dan Ervi Rahmadani

--- Halaman ini sengaja dikosongkan --- 